\title{
Cooperative Promotion both in Knowledge and Ability during Educating and Training of Excellent Engineer
}

\author{
S.P. CHEN*, W.X. WANG, W.BAI, Z.Q. CUI, M. DING, H.X. ZHANG \\ College of Materials Science and Engineering, Taiyuan University of Technology, Taiyuan, Shanxi, China
}

\begin{abstract}
It is proposed by Ministry of Education to have at least one-year internship in factory during four-year college education and training of excellent engineers, so for most pilot majors, the fourth school year is set as internship period. However it has been proved that learning of more theoretical courses that are supposed to be finished in advance has put much burden on students; meanwhile, long-time internship in welding workshop would also bring safety concerns. All of these factors make it difficult to proceed well. For the current problems we have encountered during students' internship, cultivating mode of outstanding engineers, aiming at cooperative improvement both in theoretical and practical ability, has been brought out and implemented based on the cognitive development of human. It is indicates that students' learning initiative is being mobilized and their ability is also being improved greatly through the cooperative improvement mode.
\end{abstract}

KEYWORD: Excellent engineers; internship; theoretical knowledge; practice ability; coordinate improvement

\section{INTRODUCITON}

Based on practical education and engineering ability, the project of "Program of educating and training of excellent engineers" is aiming at improving the college's consciousness, quality and ability of engineering. The current accepted educating and training mode is $3+1$, in which the undergraduate college students spend the whole fourth school year in workshop and are supposed to practice and improve their consciousness and quality of engineering. According to the program, our early educating and training plan includes 8-month factory-based internship with different assistance positions including technician, section chief, director and chief engineer. Students are supposed to learn about the whole process including product manufacturing, business management, quality control, sales and after-sales service and so on in order to improve their engineering ability and quality.

With the implementation of the project, the university is facing the great challenge and safety consideration. For materials processing, the hidden danger exists everywhere, especially for students who are engaged in long time internship, which also makes it difficult to balance the profit of both enterprises and students. The former has to close some section in order to make sure students are safe enough during internship while the latter prefer to watch and learn as much as possible. Moreover, the fourth school year is the key one for students. In this year, they have to spend much time in taking interviews and exams in order to get a job, or a chance to further study. All of this kind of interviews and exams are held on campus in working time, so that students in internship could not take care both. Meanwhile, during the last three years, it has also been proved that learning of more theoretical courses that are supposed to be finished in advance has put much burden on students. Without enough perceptual knowledge and practice, it's really difficult for students to learn and understanding what were taught in class actively. Aiming at above problems, based on the nature of human cognition, we presented a modified internship training mode for excellent engineers based on alternatively rising practical ability and theoretical knowledge, in which the one-year workshop internship is divided into five parts, including engineering practice, architectural aesthetic design, engineering ability and quality development, science and innovation, and business management. These five practical parts is going through the whole eight semesters accompanied by

\footnotetext{
* Corresponding author: Shaoping Chen, associate professor, Ph.D, chenshaoping@tyut.edu.cn, Tel. 86-351-6010076
} 
learning of theoretic knowledge. The result indicates a better effect that the new mode motivates the students to learn and practice more actively than ever.

\section{EXPLORATION AND IMPLEMENTATION}

With the implementation of the project, students are supposed to get basic knowledge, primary ability and comprehensive quality by educating and training, which are necessary to be excellent modern engineer. The aim of the project is to improve the college's consciousness, quality and ability of engineering. To achieve the aim and avoid the problems related to safety, profit, and effect as well, based on priority of talent cultivation of university, a rich and feasible educational program has been put forward, in which the one-year workshop internship is divided into five parts of architecture and aesthetic design, ability and quality development, scientific research and innovation practice, engineering practice, and enterprise management (the detail of the new mode is shown in Figure 1).

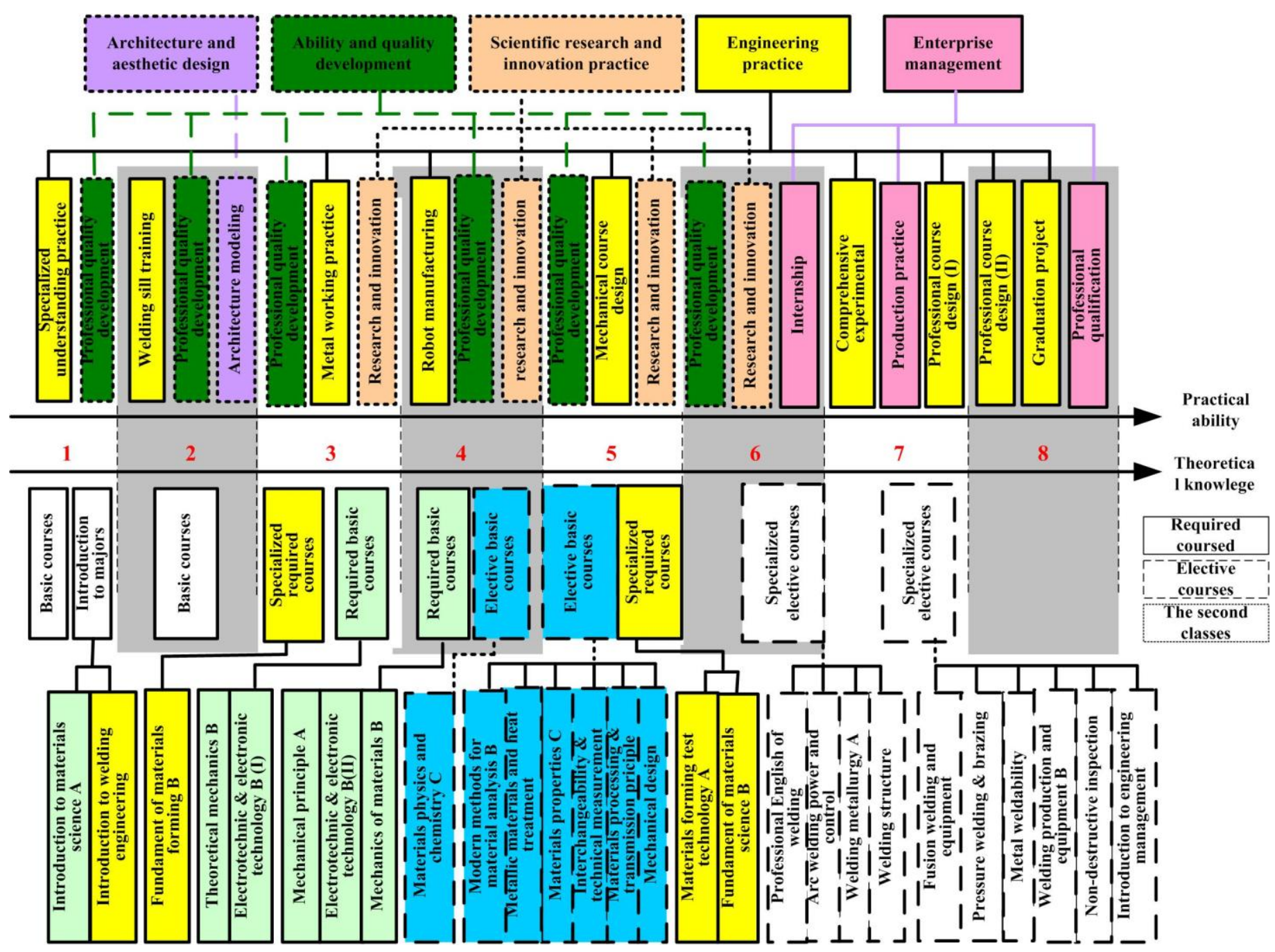

Figure 1. New educating and training mode of practical ability and theoretical knowledge, professional quality and comprehensive quality

\subsection{Promote the cognition competence step by step based on engineering practice}

The engineering practice is the most important and basic content in the whole practice module, which includes understanding practice, welding skill training, metal working practice, robot manufacturing, mechanical course design, welding engineering comprehensive experiment, professional course design and graduation project. These eight practices are arranged from the first semester through the eighth, accompanied by the professional required and elective courses, so students can get knowledge and ability as learning by doing. In order to make it more feasible, part of courses has been reformed greatly, for example, <introduction to welding engineering> and <introduction to materials science> are arranged in the first semester instead of the fourth and fifth, so the students can learn about some basic specialized knowledge in advance. Moreover, these two courses also help the students to understand some basic phenomenon and learn about the trend of materials science development, like how an electric arc is generated, how to lay 
weld, what kind of advanced materials we have discovered and so on. All of above will motivate students to further explore more knowledge and information. Meanwhile, the practical course of <welding engineering comprehensive experiment> and <professional course design> are arranged together with other professional courses, so that the students can learn more as they are trying to analyze and deal with engineering issues by watching and practicing in workshop, searching through literatures and interdisciplinary documents. As a result, both their knowledge and ability would be improved as well.

\subsection{Laying solid foundation and practicing team- work spirit}

The integrated development of excellent engineers requires not only professional knowledge and skills, but also good moral character, physical and mental quality, and team-work spirit. The undergraduate college students are facing unprecedented impact bringing about from fast development of society and technology, so it is becoming urgent and necessary for them to rationally assess the social phenomenon and evaluate themselves. It is also the foundation and basic quality for engineer talent to keep physical and psychology health. In the new model, the basic content of quality and ability cultivation is put in the course of <ability and quality development>, which lasts from the first semester through the sixth. The course includes three parts of growth concept (adaptability and safety training for freshman), interactive growth quality education (inner safety and literature quality), and intrusive growth puzzle education (team-work spirit and career planning). In each part there are six lectures and six activities, which share different topics of how to understand the relationship among nature, society and individual; how to face defeat and success in your life; when to start your career planning; how to keep yourself strong-willed and hopeful. This section will be helpful for students to fulfill their dreams and pursue the ideal.

\subsection{Cultivating architecture aesthetic feeling and exploring engineering design capability}

In order to cultivate their esthetic feeling and explore their design capacity, students are advised to take the course of <Architecture Modeling>, wihch is arranged in the second semester. In the course students are encouraged to measure and modle landmark architectures and classic products, eg. Nest stadium, Eiffel tower, aircraft carrier, United States Capitol, Qiao's Manor, etc. During the section, the students are encouraged to work together to complete measuring, structure breaking down, cost accounting, materials purchasing, cutting and rebuilding. The course would help students to practice their work-team spirit and cultivate their aesthetic feeling and design capacity, to understand the relationship among science, technology and engineering. The course makes the practice section richer and more attractive.

\subsection{Discovering interdisciplinary and expanding innovation thinking}

Except specialized course design, the cultivation of scientific research and innovation goes through the whole college period. The course <research and innovation> lasts from the third semester through the sixth semester; Students are encouraged to select a project according to their interest without limitation. Interdisciplinary research and project based on engineering issue are encouraged. Students can get financial support by building their own research group, and they are also welcome to join any professional research group on campus. From this training section the students are supposed to improve their level of understanding in both themselves and research, which would be helpful to for them to confirm the goal of development.

\subsection{Improving managerial capacity and widening international vision}

In the eighth semester, training and qualification of International Welding Engineer, IWE, is being carried out. Some experienced enterprise mentors are employed to give lectures to IWE and also the course of <introduction to enterprise management>. Combining with professional knowledge, they teach more about enterprise management, international standard (DIN, ISO and ASME), production, structure and design, materials and process, systematically, so that students can improve their engineering quality and international competitiveness by learning to analyze and resolve international engineering cases.

\subsection{Devoting to workshop internship and cultivating engineering quality}

When all of practice sections mentioned above have been accomplished, students will take a 8-week internship in national-level educating and training bases aiming at different welding products and structures, e.g., welding power source, crane, boiler, and engine They start with assistant technician, and then section chief, director and chief engineer, successively, each one lasts for two weeks. In the assistant technician period, students are required to assist the technician in workshop by making processing documentation and technical drawing, and learn about how to explain and resolve engineering issues. Then they will spend two weeks 
working as assistant section chief. During this period, students are required to know well about how to deal with different tasks coordinately in order to guarantee the maximum profits and efficiency, and then make it practicable by scheduling the production file. Then two-week internship as chief of workshop will be taken. During this period the students will learn how to coordinate tasks distribution and make junctions between different sections; how to resolve simple technical problems and make production cost budget. The last two weeks they will work as assistant chief engineer, students are required to master the whole productive process of some product, and to assist the chief engineer setting technology development, signing technical contract and selling product.

\section{RESULTS AND EFFECTS}

\subsection{Built the scientific educating and training plan based on the memory law}

Based on physiological feature and nature law, a new learning mode has been built which follows the nature law better. In the new plan, the practice learning and theoretical learning are alternatively rising. This would help students to build up their own knowledge base from active self-study by encouraging them to gain knowledge and quality. It has been proved that in the new one students show more actively instead of being tired and bored of the learning process in the old mode that is induced by lower efficiency, singleton learning pattern and dispersed knowledge. As a result, the new educating and training mode is feasible and effective when the implementation is following the aim better and is meaningful for cultivation of excellent engineer proves that it. This will be of great importance to the cultivation of excellent engineer.

\subsection{Keeping the practice ongoing and improving ability continuously}

The greatest characteristic of the new educating and training mode is that the quality, capacity and ability are to be built up in several different ways. It begins at the first semester and lasting till the end of the college study, which means students are keeping building up their character and ability consciously all the time. It is aiming at improving students' practice ability, engineer quality and cognition by building the practice platforms, e.g., "quality development", "engineering architecture modeling", "welding skill training" "scientific research and innovation", other construction of the nation-level specialized platform includes "how the steel was tempered" and "IWE training and qualification".

\subsection{Reformed internship mode by taking both profits of enterprises and students into account}

Although the whole workshop internship is only 8 weeks, it doesn't affect the effects because they have experienced and learned much from previous courses. In the 8-week workshop internship, students are required to finish the whole internship according to manufacturing process (parts-assembling-testsale) under supervision of the chief engineer. So they can learn about how the manufacturing and quality process control works; how to communicate efficiently with customers before and after sale. In the graduation project at the eighth semester, the experienced mentors form enterprises are employed to give lectures about engineering practice, and also what kind of talents enterprise need. Based on university-enterprise integration, the students would gain much information in advance which would be helpful for them to determine what kind of job fit them well in future.

\subsection{Motivating innovation by setting up exhibition platform for design}

Several "college design works show" has been hold on campus, part of works were collected by enterprise and individual including structure modeling, research idea and innovation. It provides students opportunity to show their works to the world and also helps freshmen to learn about the educating and training mode they will take. The show is also supported by some enterprises due to its innovation.

\section{PROSPECT}

\subsection{Coordinative process of practice learning and theoretic learning}

Combining the specialty of major, based on physiology and pedagogy, a new educating mode has been discovered by expanding and making full use of resources related to practice on campus. A alternative rising mode between practical learning and theoretical learning has been applied to improve students' comprehensive quality and capacity. Moreover, separated comprehensive experiment course is also helpful to avoid the discordance between practical teaching and theoretical teaching.

\subsection{Clearing the problem of inadequate internship}

Due to safety and confidentiality, internship is not very welcome in enterprises. The implementation of the new educating and training mode would be helpful for students to increase their safety and confidentiality cognition. The internship is arranged in the seventh semester when the students have accomplished most of practice and theoretic 
learning, so they can understand and adapt to new situation, and they would also be helpful to give some advices and provide help considering of new products or to improve the whole manufacturing process. By the way, good performance will help them to build their brands during internship and become more confident.

\subsection{Innovation cognition and ability being improved step by step}

Basic courses and professional courses advance side by side, which helps student learning about the basic knowledge, the trend of their major, and cultivate interest. Practice learning and theoretical learning advance alternatively and coordinately, so they use theory to guide the practice and then apply theory to practice, as a result both theoretic and practical skill would be improved. Laying firm foundation and developing interdisciplinary courses to help students to widen thinking, culture and ability; exploring the second and third classes by university-enterprise regeneration to support specialized course design, internship and graduation project based on practice platform of workshop. All of this would be beneficial for students to improve their engineering cognition, quality and ability. When the whole process has been finished, some outstanding projects will be presented to all students from freshman to junior, the question and answer section help students to have full communication and deep understanding.

\section{ACKNOWLEDGMENTS}

This work was supported by the Education Program of Higher Learning Institutions of Shanxi (No.J2013013)

\section{REFERENCES}

[1] Zhang, J.W. \& Bai W. et al. 2012. Deepen reform according to the reality implement the research and practice of "outstanding engineers training plan" in taiyuan university of technology to education. China University Teaching 6: 67-69.

[2] Zhou Y. 2011. Implementing excellent engineers training plan and develop innovation talents. China University Teaching 8: 11-13.

[3] Hu, Y.H. \& Fan, X.H., et al. 2013. Cultivating mode of excellent engineer based on "knowledge + capacity + quality". China University Teaching 6: 24-25.

[4] Lin, J. 2012. Characteristics of competitive advantage of excellent engineer. Research in Higher Education of Engineering 6: 7-22. 